\title{
Role of Vibrio polysaccharide (vps) genes in VPS production, biofilm formation and Vibrio cholerae pathogenesis
}

\author{
Correspondence \\ Fitnat H. Yildiz \\ yildiz@metx.ucsc.edu
}

Received 2 April 2010

Accepted 10 May 2010

\author{
Jiunn C. N. Fong, ${ }^{1}$ Khalid A. Syed, ${ }^{2}$ Karl E. Klose ${ }^{2}$ and Fitnat H. Yildiz ${ }^{1}$ \\ ${ }^{1}$ Department of Microbiology and Environmental Toxicology, University of California, Santa Cruz, \\ Santa Cruz, CA 95064, USA \\ ${ }^{2}$ Department of Biology, The University of Texas at San Antonio, South Texas Center for Emerging \\ Infectious Diseases, San Antonio, TX 78249, USA
}

\begin{abstract}
Biofilm formation enhances the survival and persistence of the facultative human pathogen Vibrio cholerae in natural ecosystems and its transmission during seasonal cholera outbreaks. A major component of the $V$. cholerae biofilm matrix is the Vibrio polysaccharide (VPS), which is essential for development of three-dimensional biofilm structures. The vps genes are clustered in two regions, the $v p s-I$ cluster ( $v p s U, v p s A-K$, VC0916-27) and the vps-II cluster (vpsL-Q, VC093439), separated by an intergenic region containing the $r b m$ gene cluster that encodes biofilm matrix proteins. In-frame deletions of the vps clusters and genes encoding matrix proteins drastically altered biofilm formation phenotypes. To determine which genes within the vps gene clusters are required for biofilm formation and VPS synthesis, we generated in-frame deletion mutants for all the vps genes. Many of these mutants exhibited reduced capacity to produce VPS and biofilms. Infant mouse colonization assays revealed that mutants lacking either vps clusters or $r b m A$ (encoding secreted matrix protein $\mathrm{RbmA}$ ) exhibited a defect in intestinal colonization compared to the wild-type. Understanding the roles of the various vps gene products will aid in the biochemical characterization of the VPS biosynthetic pathway and elucidate how $v p s$ gene products contribute to VPS biosynthesis, biofilm formation and virulence in V. cholerae.
\end{abstract}

\section{INTRODUCTION}

Vibrio cholerae causes the diarrhoeal disease cholera (Kaper et al., 1995) and is a natural inhabitant of aquatic ecosystems (Faruque et al., 1998). V. cholerae's ability to cause epidemics is linked to its ability to survive in its natural habitats, which is enhanced by its ability to form matrix-enclosed, surface-associated communities, known as biofilms (Alam et al., 2006; Faruque et al., 1998). In aquatic habitats, $V$. cholerae can be isolated from surfaces of phytoplankton, zooplankton, aquatic plants, crustaceans and insects, as well as sediments (Broza et al., 2005; Halpern et al., 2004; Huq et al., 1983, 1986, 1995), and biofilm formation facilitates environmental survival of the pathogen. Biofilms are also critical for the transmission and infectivity of $V$. cholerae. Removal of particles $>20 \mu \mathrm{m}$ in diameter from water can reduce cholera incidence (Colwell et al., 2003; Huo et al., 1996). Furthermore, stool samples of cholera patients contain both biofilm-like aggregates and planktonic forms of V. cholerae (Faruque et al., 2006), and

Abbreviations: CSLM, confocal scanning laser microscopy; VPS, Vibro polysaccharide.

A supplementary table of primers is available with the online version of this paper. the average infectivity of the aggregate form is significantly higher than that of planktonic cells (Faruque et al., 2006). Altogether, these studies indicate the importance of the biofilm growth mode in both the intestinal and aquatic phases of $V$. cholerae's life cycle.

Formation of mature biofilms requires the production of extracellular matrix components. A major component of the $V$. cholerae biofilm matrix is VPS (Vibrio polysaccharide) exopolysaccharide, which is required for the formation of mature biofilm structures (Yildiz \& Schoolnik, 1999), while matrix proteins, in particular $\mathrm{RbmA}, \mathrm{RbmC}$ and Bap1, are required for maintaining the structural integrity of the wild-type biofilm (Fong \& Yildiz, 2007; Fong et al., 2006). VPS was first isolated from a rugose wild-type strain of $V$. cholerae that exhibited enhanced capacity to produce VPS, and consequently enhanced biofilm formation compared to the smooth wild-type strain. VPS of $V$. cholerae O1 El Tor strain A1552 contains glucose, galactose, $\mathrm{N}$-acetylglucosamine and mannose, and the genes required for VPS synthesis were identified through transposon mutagenesis (Yildiz \& Schoolnik, 1999). The vps genes are clustered in two regions on the large chromosome of $V$. cholerae O1 El Tor [vpsU (VC0916), vpsA-K (VC0917-27) (vps-I cluster); and $v p s L-Q$ (VC0934-9) (vps-II cluster)]. 
However, it is not known if all the genes within the $v p s-\mathrm{I}$ and $v p s-$ II clusters are required for biofilm formation and VPS production.

Several studies suggest that VPS is produced during infection and could contribute to in vivo colonization and survival. It has been shown that $v p s H$ (VC0924), involved in VPS production, is induced during in vivo growth in an infant mouse model system (Lee et al., 2001). Furthermore, an in vivo expression technology (IVET) screen performed in human volunteers to identify genes expressed during infection revealed that several $v p s$ genes, namely $v p s A$ (VC0917), $v p s B$ (VC0918), $v p s C$ (VC0919) and $v p s N$ (VC0936), are expressed during human infection (Lombardo et al., 2007). In vivo-induced antigen technology (IVIAT) has also shown that sera from cholera patients recognize VpsH (VC0924), which is required for VPS production (Hang et al., 2003). Hung et al. (2006) reported that bile acids stimulate $v p s$ transcription and in vitro biofilm formation. A recent study has also shown that both planktonic and aggregated forms (which are predicted to result from in vivo biofilms) of $V$. cholerae are shed in human stools (Faruque et al., 2006). In addition, it was recently shown that VpsR, the master regulator of biofilm formation and $v p s$ expression, directly activates transcription of aphA, which encodes a positive transcriptional regulator of virulence gene expression in V. cholerae (Lin et al., 2007). Taken together, these studies strongly suggest that $v p s$ genes are expressed and probably important in vivo.

In this study, we generated in-frame deletions of all the $v p s$ genes located in the $v p s-\mathrm{I}$ and $v p s$-II clusters and determined the role of these VPS proteins in biofilm formation and VPS biosynthesis. We also analysed the contribution of VPS and matrix proteins to in vivo fitness of $V$. cholerae.

\section{METHODS}

Bacterial strains, plasmids and culture conditions. The bacterial strains and plasmids used in this study are listed in Table 1. All V. cholerae and Escherichia coli strains were routinely grown aerobically in Luria-Bertani (LB) medium (1\% tryptone, $0.5 \%$ yeast extract, $1 \%$ $\mathrm{NaCl})$ at $30{ }^{\circ} \mathrm{C}$ and $37{ }^{\circ} \mathrm{C}$ respectively, unless otherwise noted. Agar medium contained $1.5 \%$ granulated agar (Difco). Concentrations of antibiotics used were as follows: ampicillin, $100 \mu \mathrm{g} \mathrm{ml}^{-1}$; rifampicin, $100 \mu \mathrm{g} \mathrm{ml}^{-1}$; gentamicin, $50 \mu \mathrm{g} \mathrm{ml}^{-1}$.

Recombinant DNA techniques. Restriction enzymes, DNA modification enzymes and Phusion High-Fidelity DNA polymerase were purchased from New England Biolabs. PCRs were carried out with primers purchased from Bioneer USA Corporation, listed in Supplementary Table S1, available with the online version of this paper. DNA sequencing was carried out by the Sequetech Corporation.

Generation of in-frame deletion mutants. Deletion mutants were generated according to the protocol previously published (Fong et al., 2006; Fullner \& Mekalanos, 1999). The DNA sequences of the constructed deletion plasmids were verified by DNA sequencing.
Colony morphology and pellicle formation analyses. For analysis of corrugated colony morphology development, cultures grown overnight at $30{ }^{\circ} \mathrm{C}$ with shaking (200 r.p.m.) were serially diluted with LB medium and $100 \mu \mathrm{l}$ aliquots of the diluted cultures were plated onto LB agar medium. The cultures were incubated at $30{ }^{\circ} \mathrm{C}$ for 2 days. For analysis of pellicle formation, glass culture tubes $(18 \times 150 \mathrm{~mm})$ containing $5 \mathrm{ml} \mathrm{LB}$ medium were inoculated with overnight-grown cultures, resulting in a 200 -fold dilution. The tubes were incubated at $30{ }^{\circ} \mathrm{C}$ under non-shaking conditions for 2 days. Assays were repeated with at least two different biological replicates.

VPS immunoblot assays. Isolation of crude VPS from wild-type and mutant strains and immunoblot analyses of the extracted VPS were carried out according to a protocol similar to those previously published (Enos-Berlage \& McCarter, 2000; Fong \& Yildiz, 2007; Yildiz \& Schoolnik, 1999). Briefly, overnight-grown cultures on LB agar medium were harvested and resuspended in PBS. Normalization was carried out by adjusting each culture to the same $\mathrm{OD}_{600}$, measured with a Beckman Du Series 500 spectrophotometer. Equal volumes of the cultures were pipetted into Erlenmeyer flasks and the suspension was incubated overnight at $4{ }^{\circ} \mathrm{C}$, shaking at 100 r.p.m. Crude VPS supernatant was separated from the bacterial cells and debris by centrifugation twice at $20000 \mathrm{~g}$ for $30 \mathrm{~min}$ and precipitated with 3 volumes of ethanol at $-20{ }^{\circ} \mathrm{C}$ overnight. Crude VPS was pelleted by centrifugation at $20000 \mathrm{~g}$ for $30 \mathrm{~min}$, washed with $70 \%$ ethanol, air-dried and resuspended in $500 \mu \mathrm{l}$ water. Purified VPS from the wild-type rugose variant was used as a positive control and for quantification. Purified VPS was isolated as described above with additional purification steps published previously (Fong \& Yildiz, 2007). Briefly, crude VPS pellet was resuspended in nuclease buffer (40 mM Tris/HCl pH 8.0, $10 \mathrm{mM} \mathrm{MgCl}_{2}, 2 \mathrm{mM} \mathrm{CaCl}_{2}, 0.05 \%$ $\mathrm{NaN}_{3}$ ). DNase I and RNase A were added to the VPS suspension at final concentrations of 2 units $\mathrm{ml}^{-1}$ and $50 \mu \mathrm{g} \mathrm{ml} \mathrm{m}^{-1}$, respectively, followed by incubation at $37{ }^{\circ} \mathrm{C}$ shaking for $8 \mathrm{~h}$. Proteinase $\mathrm{K}$ was then added at a final concentration of $200 \mu \mathrm{g} \mathrm{ml}^{-1}$, and the suspension was further incubated with shaking overnight at $37^{\circ} \mathrm{C}$. Phenol/chloroform extractions (equal volumes) were carried out, followed by precipitation with 3 volumes of ethanol, washing with $70 \%$ ethanol, and solubilization in water. Detoxi-Gel endotoxinremoving gel (Pierce) was used to remove contaminating lipopolysaccharides (LPS) according to the manufacturer's instructions and the purified VPS suspension was dialysed with water at $4{ }^{\circ} \mathrm{C}$ overnight using a Slide-A-Lyser $3.5 \mathrm{~K}$ MWCO dialysis cassette (Pierce). The VPS suspension was then dried using a Micro Modulyo freeze-drier (Thermo Savant), the dry weight of the VPS sample was determined and the dried purified VPS was resolubilized in water. Crude and purified VPS $(3 \mu \mathrm{l})$ was spotted onto nitrocellulose membranes and immunoblot analyses were carried out using anti-VPS antiserum and goat anti-rabbit horseradishperoxidase-conjugated antibody. The immunoblots were developed with the SuperSignal West Pico chemiluminescent kit (Pierce) and quantified using ImageQuant 5.2 software (Molecular Dynamics). VPS immunoblot analyses were carried out with two different biological replicates and at least three technical replicates. It should be noted that the VPS antibody used in this study is polyclonal, with undefined epitopes. As such, the immunoblot assay was used as a phenotypic screen to identify mutants that cannot produce 'wildtype' VPS and not for determining the effect of a given mutation on the VPS structure.

Quantitative biofilm assays. Biofilm formation assays were carried out in PVC microtitre plates (BD Falcon) with $100 \mu$ l of overnightgrown cultures diluted to an $\mathrm{OD}_{600}$ of 0.04 . The microtitre plates were incubated at $30{ }^{\circ} \mathrm{C}$ for $8 \mathrm{~h}$. Crystal violet staining and ethanol solubilization were carried out as previously described (Fong et al., 2006; Yildiz et al., 2001). Absorbance of the solubilized crystal violet stain was measured at $595 \mathrm{~nm}$ using a VersMax Tunable Microplate 
Table 1. Bacterial strains and plasmids used in this study

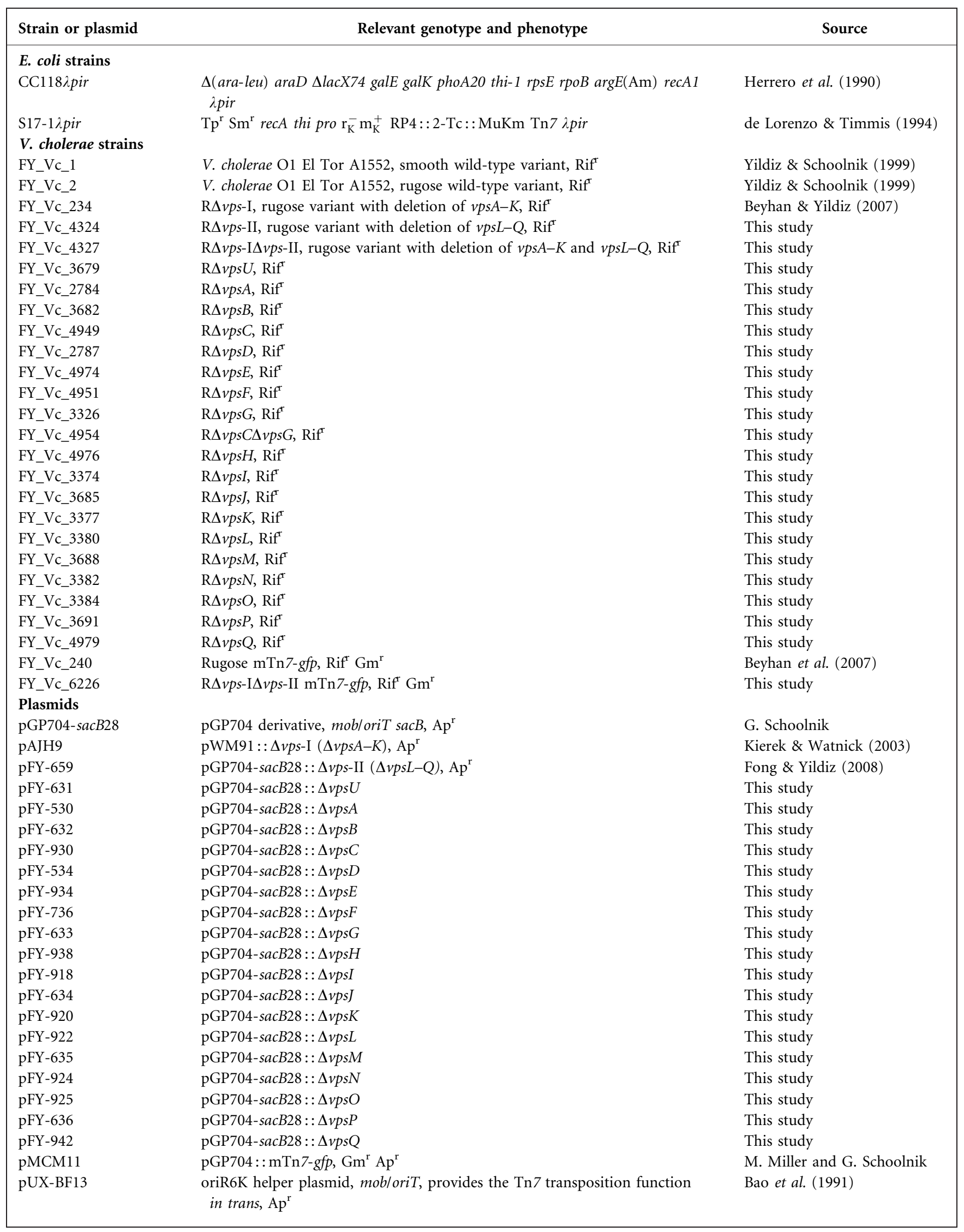


Reader (Molecular Devices). The assays were repeated with at least two different biological replicates and at least five technical replicates.

Generation of GFP-tagged strains and confocal scanning laser microscopy (CSLM). $V$. cholerae wild-type and deletion strains were tagged with green fluorescent protein (GFP) according to the procedure previously described (Fong et al., 2006). Flow-cell experiments were carried out at room temperature as described previously (Beyhan et al., 2007). Images were acquired using a Zeiss Axiovert $200 \mathrm{M}$ laser scanning microscope. 3D images of the biofilms were reconstructed using IMARIS software (Bitplane) and quantified using COMSTAT (Heydorn et al., 2000). Experiments were carried out with at least two biological replicates.

Infection studies. The infant mouse intestinal colonization model system was used in the single-strain infection experiment. Oral administration of $10^{6}$ exponential-phase $V$. cholerae wild-type variants or deletion mutants (unable to produce biofilm matrix components) to 4-5-day-old CD-1 suckling mice was carried out. At $20 \mathrm{~h}$ post-infection, the mice were sacrificed and their small intestines were removed and homogenized. Intestinal homogenates were serially diluted and plated onto selective agar. The number of bacteria per intestine was quantified by colony counting and used to determine intestinal colonization of the mutant strain. One-way ANOVA (Kruskal-Wallis test) was performed to determine statistically significant differences. Individual groups were then compared using the Mann-Whitney non-parametric $t$-test; a $P$-value of $\leqslant 0.05$ was considered significant (Prism 5, GraphPad Software).

\section{RESULTS AND DISCUSSION}

\section{Molecular analysis of vps gene clusters}

A major component of $V$. cholerae biofilm matrix is the VPS exopolysaccharide. VPS production is mediated by proteins encoded by the $v p s$ genes, which are organized into $v p s-\mathrm{I}$ and $v p s$-II clusters on the large chromosome, separated by an $8.3 \mathrm{~kb}$ intergenic region containing six genes (Fong \& Yildiz, 2007; Fong et al., 2006; Yildiz \& Schoolnik, 1999). There are $18 v p s$ genes, 12 of which are located in the $v p s$-I cluster ( $v p s U, \mathrm{VC} 0916$; $v p s A-K, \mathrm{VC} 0917-27$ ), while the other six are located in the $v p s-$ II cluster ( $v p s L-Q, \mathrm{VC} 0934-9)$ (Fig. 1). To determine if all the $v p s$ gene products are required for biofilm formation, we generated in-frame deletion mutants for each $v p s$ gene in the wild-type rugose genetic background (hereafter referred as $\mathrm{R} \Delta$ ). We also constructed mutant strains containing deletions of the first and/or second $v p s$ clusters [R $\Delta v p s-\mathrm{I}(v p s A-K), \mathrm{R} \Delta v p s-\mathrm{II}(v p s L-Q)$ and $\mathrm{R} \Delta v p s-$ $\mathrm{I} \Delta v p s-\mathrm{II}]$. We then characterized the mutants for colony morphology, pellicle formation, biofilm formation and VPS production (Table 2). It is important to note that the deletion strains do not exhibit growth defects when compared to the parental wild-type strain (data not shown).

The rugose wild-type forms corrugated colonies (Fig. 2) and a robust pellicle (Fig. 3), and has increased capacity to form a biofilm (Fig. 4a) and produce VPS (Fig. 4b, c). We termed these phenotypes 'rugosity-associated phenotypes'. Mature biofilm formed by the rugose wild-type also exhibited the characteristic elaborate 3D structures as analysed by CSLM (Fig. 5). We first characterized strains lacking the $v p s$ clusters (R $\Delta v p s$-I, R $\Delta v p s$-II and $\mathrm{R} \Delta v p s$ I $\Delta v p s$-II). These mutant strains formed flat and smooth colonies (Fig. 2), and exhibited a marked decrease in the production or secretion of VPS (Fig. 4b, c), and reduction in the ability to form pellicles (Fig. 3) and biofilms (Fig. 4a). CSLM analysis of biofilms of the rugose wild-type and $\mathrm{R} \Delta v p s-\mathrm{I} \Delta v p s-\mathrm{II}$ revealed that the latter is unable to form the elaborate 3D mature biofilm structures (Fig. 5). COMSTAT analysis revealed that total biomass, and mean and maximum thicknesses, are lower in R $\Delta v p s$-I $\Delta v p s$-II compared to the rugose wild-type, particularly after $24 \mathrm{~h}$ (Table $3)$. Strains carrying in-frame deletions of either the $v p s$-I or $v p s$-II cluster also form biofilms resembling that of R $\Delta v p s-$ I $\Delta v p s$-II (data not shown).

We then analysed the rugosity-associated phenotypes of the individual $v p s$ deletion mutants. Based on the predicted amino acid sequences and domains of the vps gene products and their predicted functions, we can group these VPS proteins into six classes (Table 2). Class I consists of proteins that are predicted to be required for production of nucleotide sugar precursors. VpsA is predicted to encode UDP- $\mathrm{N}$-acetylglucosamine 2-epimerase while $\mathrm{VpsB}$ is predicted to encode UDP- $N$-acetyl-Dmannosaminuronic acid dehydrogenase. UDP- $N$-acetylglucosamine 2-epimerase catalyses the interconversion of UDP- $N$-acetyl-D-glucosamine to UDP- $N$-acetyl-D-mannosamine. The latter is then converted to UDP- $N$-acetyl-Dmannosaminuronic acid by UDP- $N$-acetyl-D-mannos-

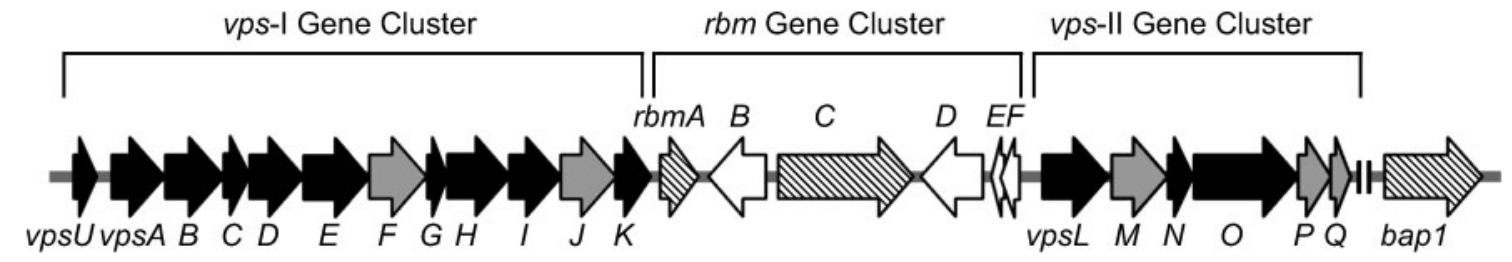

Fig. 1. Genomic organization of genes involved in VPS and matrix protein production in $V$. cholerae. Loci of the genes encoding proteins involved in VPS biosynthesis ( $v p s-I$ and vps-II clusters) and genes encoding matrix proteins ( $r b m$ cluster and bap 1) on the $V$. cholerae chromosome are depicted. Arrows represent genes predicted to be involved in VPS biosynthesis (black), encoding hypothetical proteins (grey) and encoding matrix proteins RbmA, RbmC and Bap1 (hatched), and other genes found in the vps-intergenic region (white arrows). Unlinked chromosomal DNA region is indicated (II). Illustration is not to scale. 
Table 2. Predicted function of the vps gene products and phenotypic characteristics of vps mutants

\begin{tabular}{|c|c|c|c|c|c|c|c|c|}
\hline Annotation & Gene & $\begin{array}{l}\text { Predicted peptide } \\
\text { length }\end{array}$ & $\begin{array}{c}\text { Colony } \\
\text { corrugation }^{\star}\end{array}$ & $\begin{array}{c}\text { Pellicle } \\
\text { formation } \dagger\end{array}$ & $\begin{array}{c}\text { Biofilm } \\
\text { formation } \neq\end{array}$ & $\begin{array}{c}\text { VPS } \\
\text { production } \$\end{array}$ & Class $\|$ & $\begin{array}{c}\text { Predicted functions/ } \\
\text { domains } \$\end{array}$ \\
\hline VC0916 & $v p s U$ & 166 & $+\#$ & $+\#$ & ++ & $+1-$ & V & $\begin{array}{l}\text { Phosphotyrosine-protein } \\
\text { phosphatase }\end{array}$ \\
\hline VC0917 & $v p s A$ & 372 & - & - & + & - & I & $\begin{array}{l}\text { UDP- } N \text {-acetylglucosamine } \\
\text { 2-epimerase }\end{array}$ \\
\hline VC0918 & $v p s B$ & 413 & - & - & + & - & I & $\begin{array}{l}\text { UDP- } N \text {-acetyl-D- } \\
\text { mannosaminuronic acid } \\
\text { dehydrogenase }\end{array}$ \\
\hline VC0919 & $v p s C$ & 184 & + & + & +++ & +++ & IV & Acetyltransferase \\
\hline VC0920 & $v p s D$ & 382 & - & - & + & - & II & Glycosyltransferase \\
\hline VC0921 & $v p s E$ & 469 & - & - & + & - & III & Polysaccharide export \\
\hline VC0922 & $v p s F$ & 406 & - & - & + & - & VI & Hypothetical protein \\
\hline VC0923 & $v p s G$ & 143 & $+\#$ & $+\#$ & ++ & + & IV & Acetyltransferase \\
\hline VC0927 & $v p s K$ & 250 & - & - & + & - & II & $\begin{array}{l}\mathrm{UDP}-\mathrm{N} \text {-acetyl-D- } \\
\text { mannosamine transferase }\end{array}$ \\
\hline VC0934 & $v p s L$ & 465 & - & - & + & - & II & Glycosyltransferase \\
\hline VC0935 & $v p s M$ & 398 & - & - & + & - & VI & Hypothetical protein \\
\hline VC0936 & $v p s N$ & 175 & - & - & + & - & III & Polysaccharide export \\
\hline VC0937 & $v p s O$ & 737 & - & - & + & - & III & Polysaccharide polymerase \\
\hline VC0938 & $v p s P$ & 235 & + & + & +++ & ++ & VI & Hypothetical protein \\
\hline VC0939 & $v p s Q$ & 144 & + & + & +++ & +++ & VI & Hypothetical protein \\
\hline
\end{tabular}

*Wild-type rugose colony corrugation $(+)$; altered colony morphology with reduced corrugation $(+\#)$; flat and smooth colony morphology $(-)$. $\dagger$ Wild-type rugose pellicle formation and structure $(+)$; altered pellicle structure $(+\#)$; no pellicle formation $(-)$.

\$Wild-type rugose biofilm formation in crystal violet staining assay $(+++)$; moderate reduction in biofilm formation $(++)$; marked reduction in biofilm formation $(+)$.

$\S$ Strong rugose wild-type signal in VPS immunoblot assay $(+++)$; moderate signal $(++)$; weak signal $(+)$; faint signal $(+/-)$; very faint signal $(-)$. IIClassification based on domains and predicted functions.

SPredicted functions and domains assigned by The Institute for Genomic Research-Comprehensive Microbial Resource (TIGR-CMR) and Universal Protein Resource (UniProt) databases.

amine/mannosaminuronic acid dehydrogenase (Kawamura et al., 1979, 1985). Since VpsA and VpsB are predicted to be involved in the production of nucleotide sugar precursors, it is not surprising that deletion of $v p s A$ and $v p s B$ resulted in strains that exhibited decreased colony corrugation (Fig. 2) and reduction in the ability to form pellicle (Fig. 3), biofilm and VPS (Fig. 4).

Class II consists of four predicted glycosyltransferases encoded by $v p s D$, $v p s I, v p s K$ and $v p s L$. VpsD and VpsI are classified as members of the glycosyltransferase family 4 (GT4), while VpsK is classified as a member of GT26 in the Carbohydrate Active Enzymes (CAZY) database (http:// www.cazy.org) (Cantarel et al., 2009). Although VpsL is not classified as part of any GT family, the Universal Protein Resource (UniProt) database (http://www.uniprot. org/) shows that VpsL contains a bacterial sugar transferase domain (PF02397), suggesting that VpsL is probably a glycosyltransferase. Glycosyltransferases catalyse the transfer of sugar moieties to specific acceptor molecules
(Campbell et al., 1997; Whitfield, 2006), forming glycosidic bonds that are predicted to be involved in initiation and/or elongation of VPS subunits (repeat units). Thus, the mutants lacking glycosyltransferase activity are unlikely to produce mature VPS. As expected, strains containing inframe deletion of these genes ( $\mathrm{R} \Delta v p s D, \mathrm{R} \Delta v p s I, \mathrm{R} \Delta v p s K$ and $\mathrm{R} \Delta v p s L$ ) exhibited flat and smooth colony morphology (Fig. 2). These mutants were also unable to form a pellicle (Fig. 3), and exhibited a significant reduction in biofilm formation and were unable to produce VPS (Fig. 4).

Class III consists of proteins encoded by $v p s E, v p s H, v p s N$ and $v p s O$ that are predicted to be involved in VPS polymerization and export. VpsE contains a predicted polysaccharide synthesis domain (PF01943), which is also found in Wzxlike proteins that are $\mathrm{O}$-antigen translocases involved in LPS export in E. coli (Marolda et al., 2004, 2006; Whitfield, 1995). Besides the presence of the loosely conserved PF01943 domain, there is very low conservation in the protein primary sequence in these Wzx-like proteins (Marolda et al., 

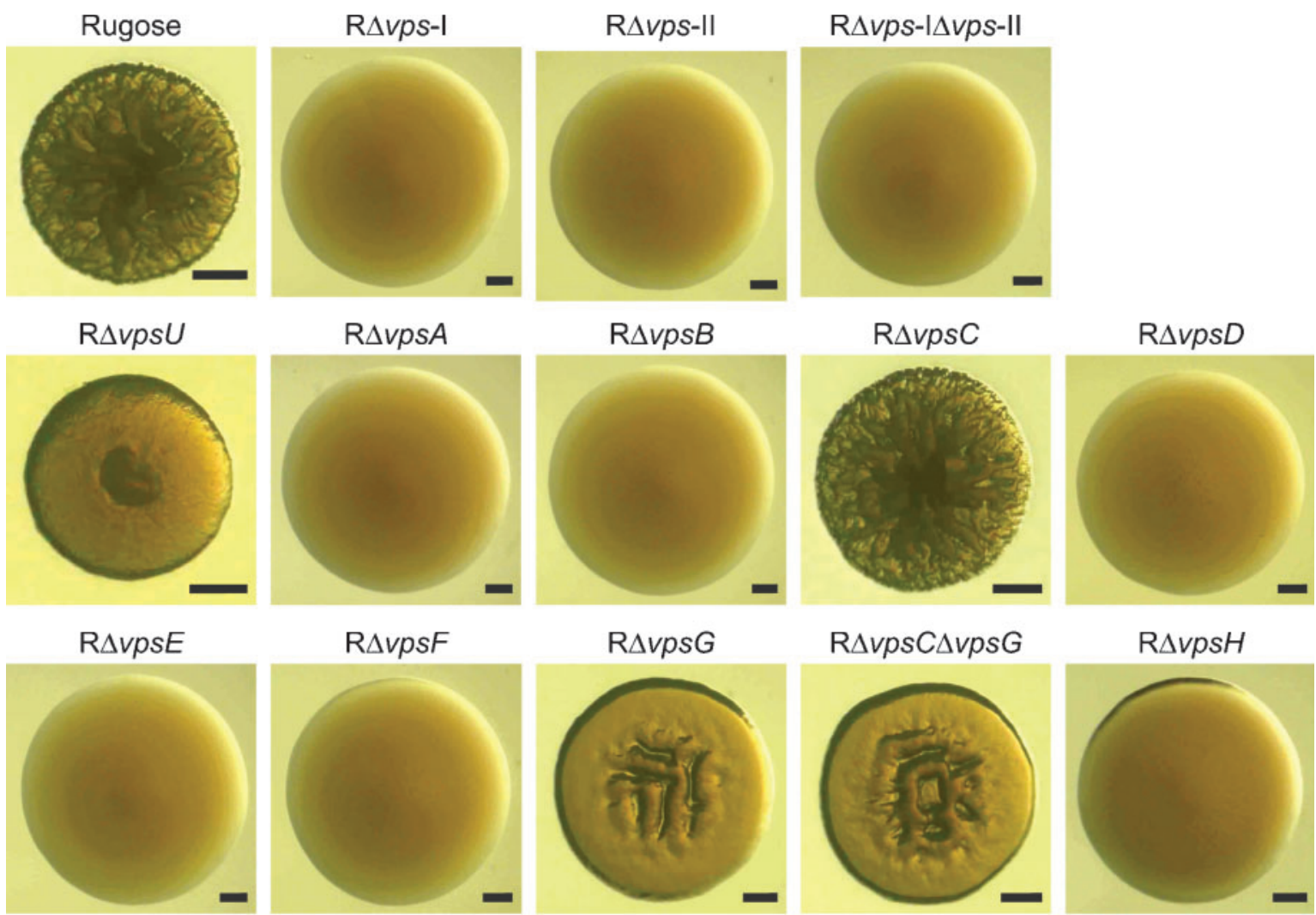

$\mathrm{R} \Delta v p s \mathrm{H}$

$\mathrm{R} \Delta v p s /$

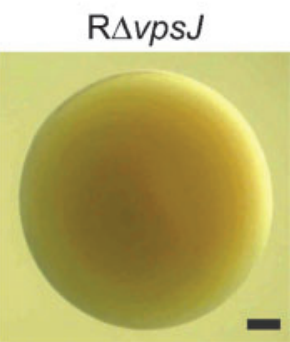

$\mathrm{R} \Delta v p s K$
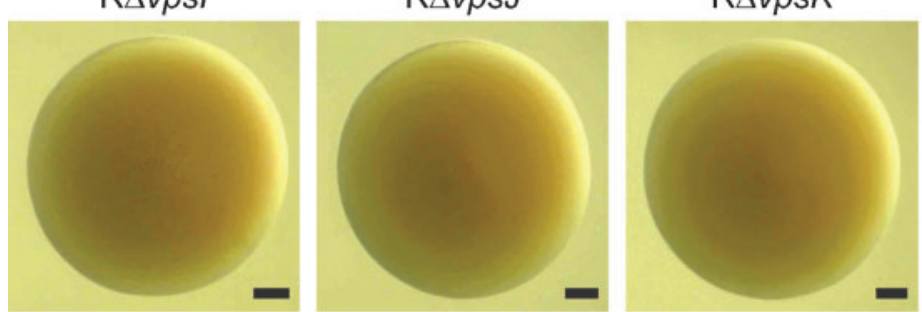

$\mathrm{R} \Delta v p s L$
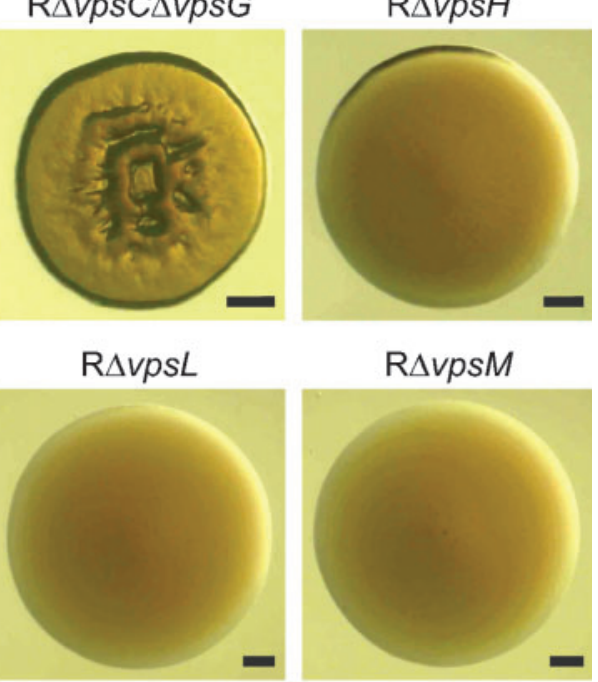

\section{$\mathrm{R} \Delta v p s M$}
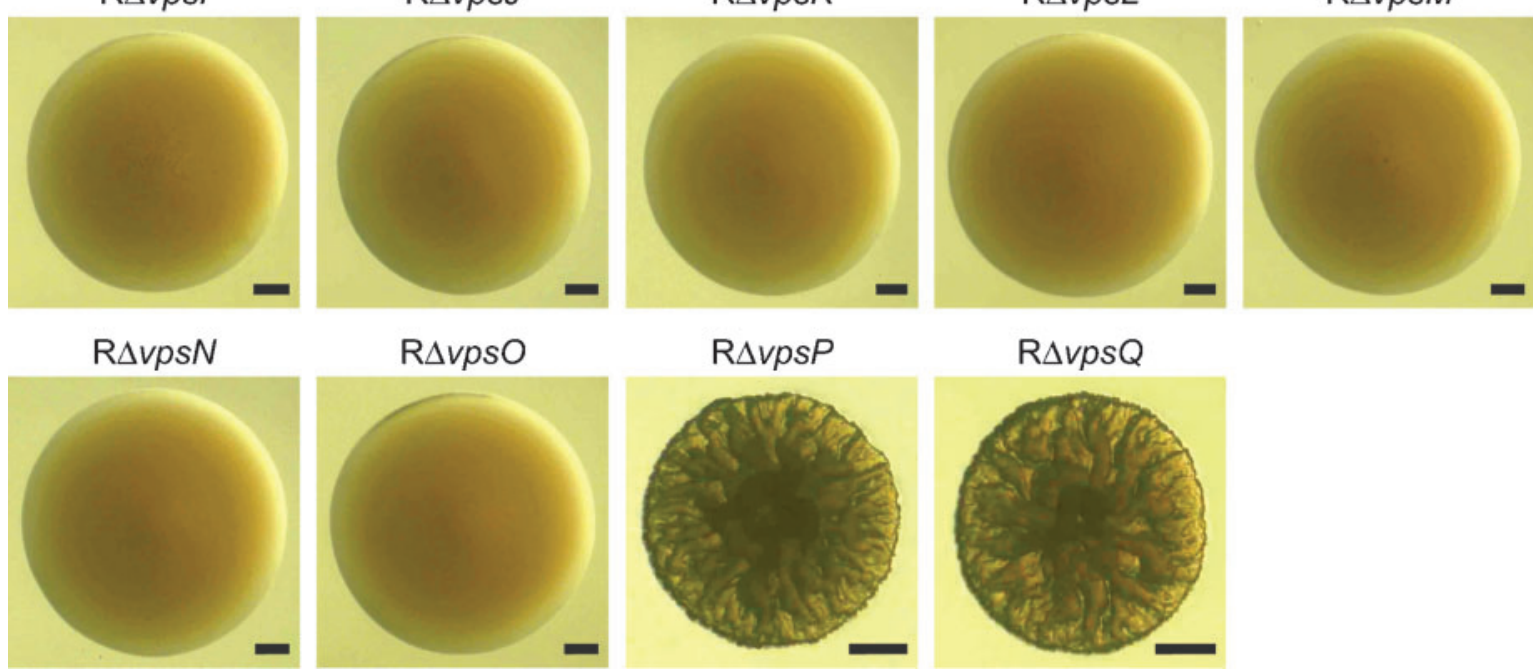

$\mathrm{R} \Delta v p s \mathrm{Q}$

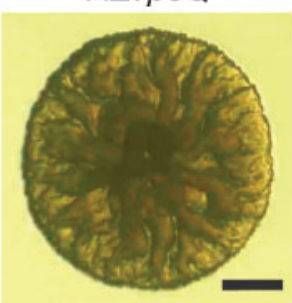

Fig. 2. Colony morphology of vps deletion mutants. Colony pictures of rugose wild-type and vps deletion mutants were taken after cultures had been incubated at $30{ }^{\circ} \mathrm{C}$ for 2 days. The assay was repeated with two biological replicates. Scale bars represent $0.5 \mathrm{~mm}$.

2006). Interestingly, PelG from Pseudomonas aeruginosa, which is involved in biofilm formation, has also been described as a Wzx-like polysaccharide transporter (Vasseur et al., 2005). Based on computational analysis, $\mathrm{VpsE}$ is likely to be a polysaccharide export protein. $\mathrm{VpsH}$ is annotated as a putative CapK protein in The Institute for Genomic Research Comprehensive Microbial Resource (TIGR-CMR) and
UniProt databases. CapK in Staphylococcus aureus is reported to be a possible capsular polysaccharide polymerase (Sau et al., 1997). VpsN is predicted by the UniProt database to encode a polysaccharide export-related protein that contains a polysaccharide export domain (PF02563), also associated with the Wzx-like proteins, suggesting that VpsN may also be involved in polysaccharide export. $\mathrm{VpsO}$ is predicted by the 

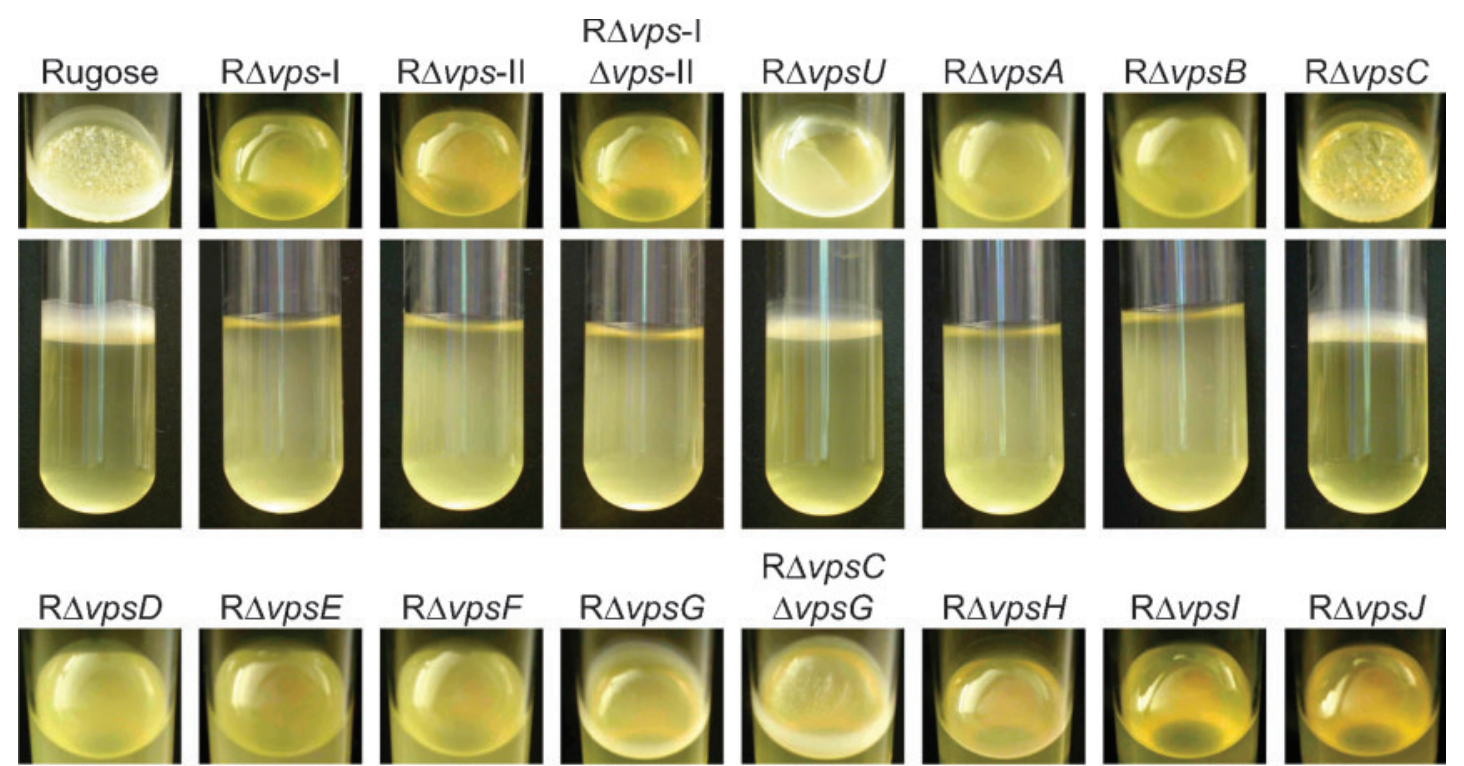

$\mathrm{R} \Delta v p s \mathrm{C}$
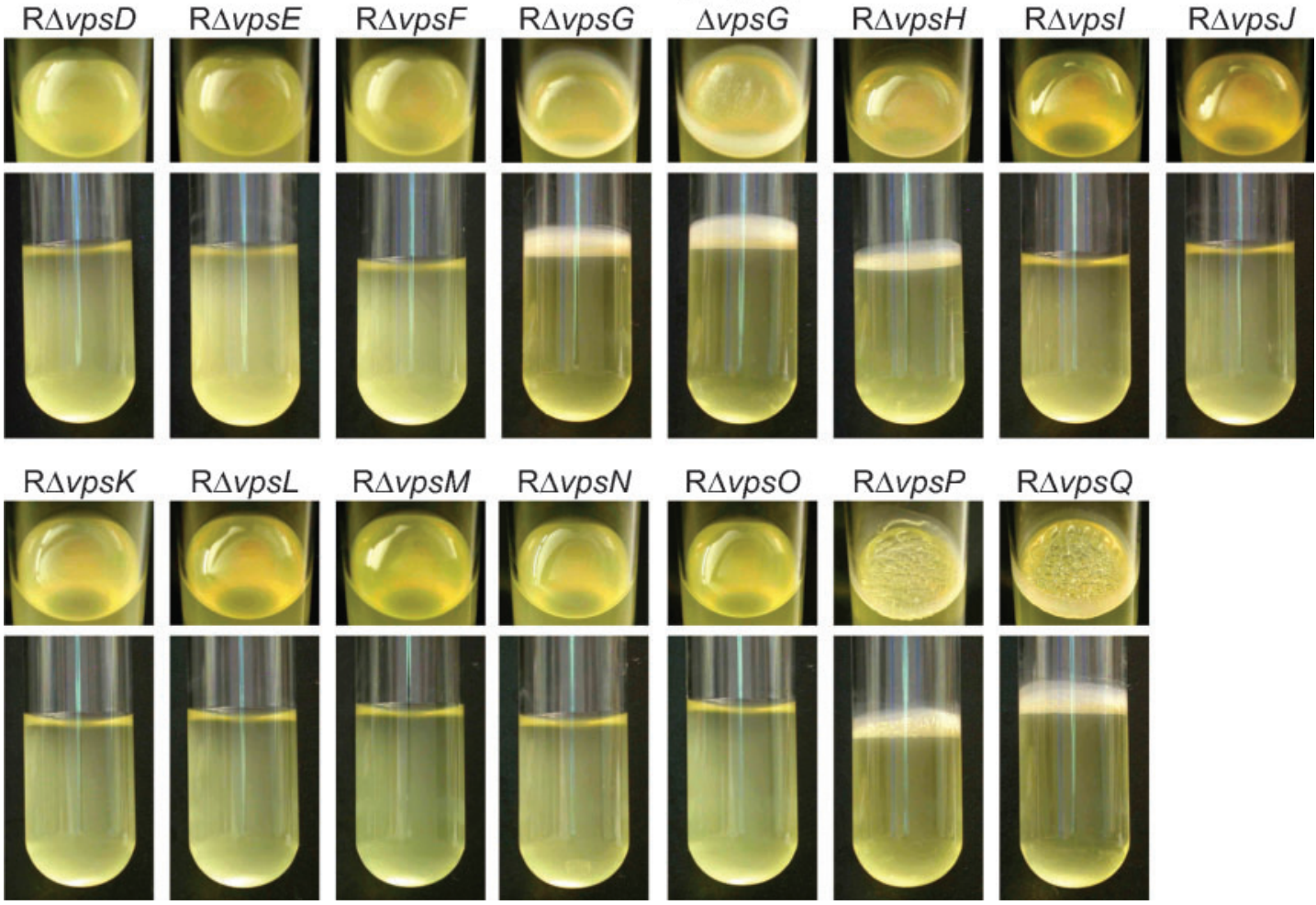

Fig. 3. Pellicle formation in $v p s$ deletion mutants. Pellicle pictures of rugose wild-type and $v p s$ deletion mutants from the top (top panels) and side (lower panels) of the cultures were taken after 2 days of incubation at $30{ }^{\circ} \mathrm{C}$. The assay was repeated with two biological replicates.

UniProt database to contain a PF02706 domain associated with the E. coli chain length determinant protein Wzz (Franco et al., 1998).

Mutants in class III may produce lipid-linked subunits of VPS, but not full-length VPS. If VPS transport takes place after complete polymerization in the cytoplasm or periplasm, VPS could accumulate in the cytoplasm or periplasm. Alternatively, unpolymerized or partially polymerized VPS may be secreted. Mutants lacking functional VpsE, VpsN and $\mathrm{VpsO}$ produced flat and smooth colonies (Fig. 2), were unable to form a pellicle (Fig. 3), and exhibited drastic reduction in biofilm formation and VPS production (Fig. 4).
Although a mutant lacking functional $\mathrm{VpsH}$ ( R $\Delta v p s H$ ) exhibited smooth colony morphology, it is important to note that the colony is more compact compared to the vpsclusters deletion mutants. Furthermore, $\mathrm{R} \Delta v p s H$ formed a pellicle with altered structures (Fig. 3, top panels) and exhibited a moderate decrease in biofilm formation (Fig. 4a). In addition, $\mathrm{R} \Delta v p s H$ produced much less VPS than the rugose wild-type, but not as little as the $v p s$-cluster deletion mutants (Fig. 4b, c), suggesting that production of VPS intermediates may still occur in $\mathrm{R} \Delta v p s \mathrm{H}$.

Class IV consists of proteins that are encoded by $v p s C$ and vpsG. VpsC and VpsG are predicted to be acetyltransferases 
(a)

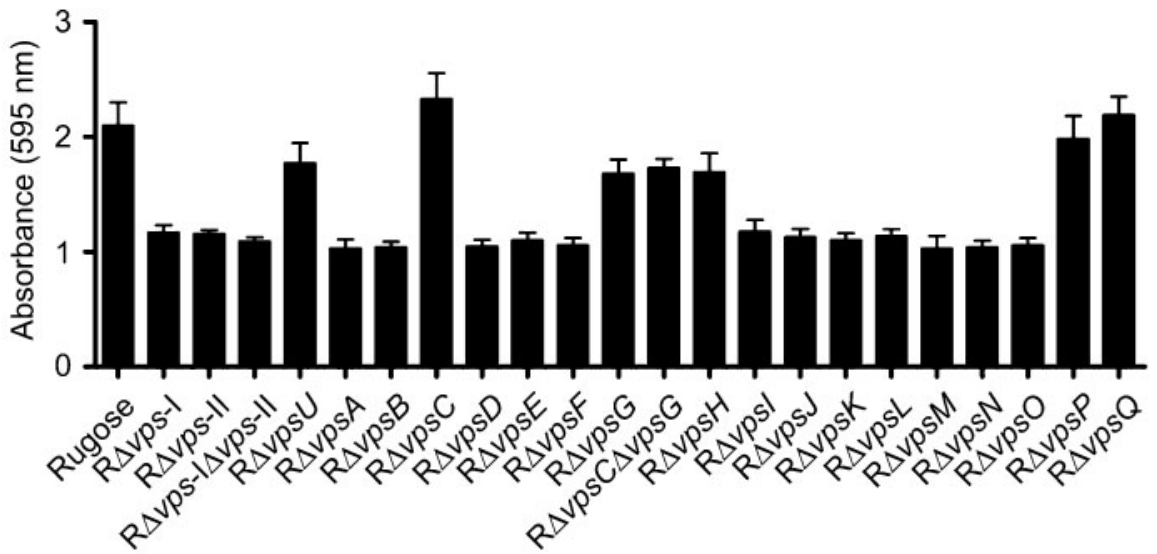

(b)

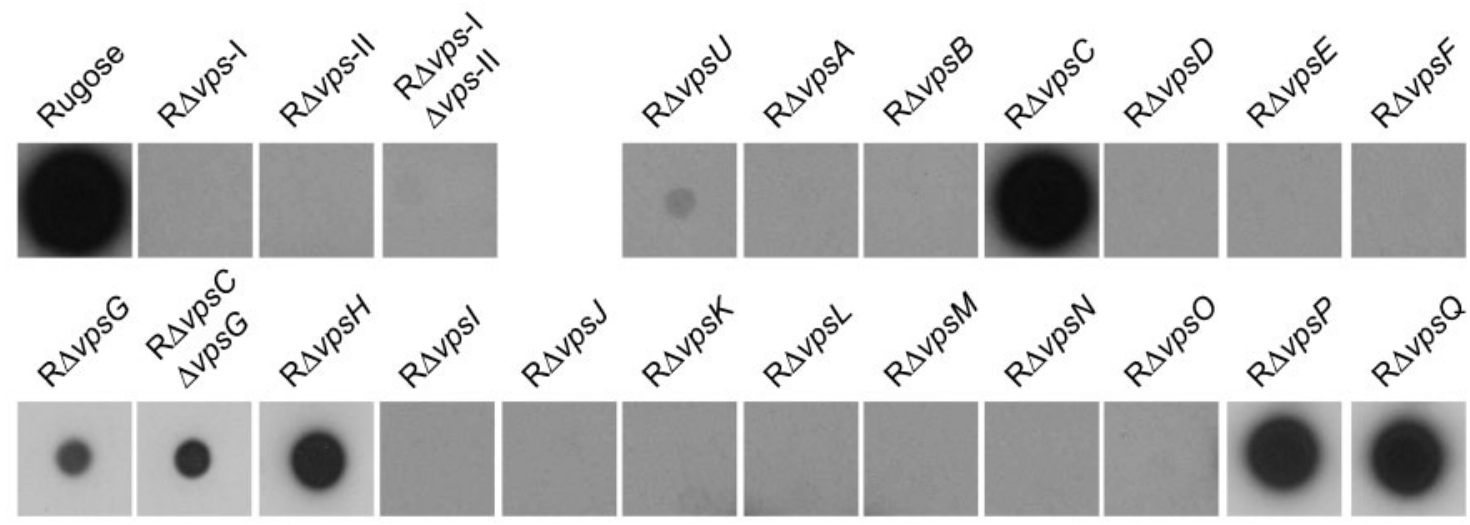

(c)

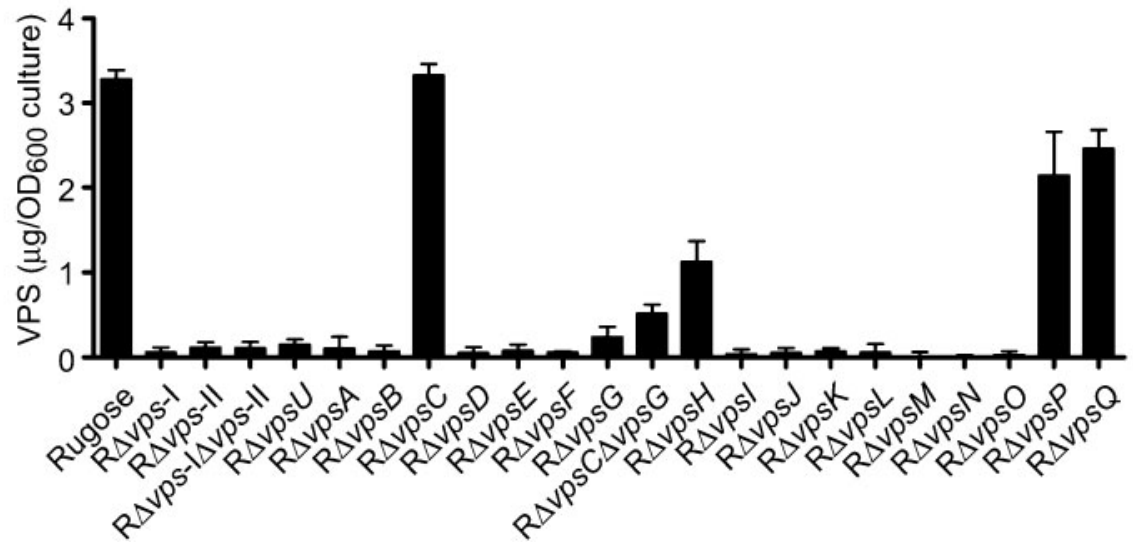

Fig. 4. Biofilm formation and VPS production in vps mutants. (a) Biofilm-forming capacities of the rugose wild-type and vps mutants were determined using the crystal violet staining assay on cultures grown at $30{ }^{\circ} \mathrm{C}$ for $8 \mathrm{~h}$ under static conditions. Results are means of at least five technical replicates and error bars represent standard deviations. (b) VPS production by rugose wild-type and vps mutants was determined by immunoblot analysis using crude VPS extract spotted on a nitrocellulose membrane and probed with an anti-VPS antiserum. (c) Quantification of VPS production in rugose wild-type and vps mutants. Purified VPS was used to quantify VPS production in the strains indicated. Results are means of at least three technical replicates and error bars represent standard deviations. Assays were repeated with two biological replicates.

involved in the addition of acetyl groups to polysaccharide. Mutants lacking the acetyltransferases were expected to produce VPS without acetyl modifications, which are likely to have different biophysical properties from those of the wild-type. $\mathrm{R} \Delta v p s G$ exhibited a significant reduction in colony corrugation but the colonies were not completely flat and smooth (Fig. 2). R $\Delta v p s G$ also formed a pellicle with altered structure (Fig. 3, top panel), and showed reduced biofilm formation and VPS production (Fig. 4). In contrast, $\mathrm{R} \Delta v p s C$ retained its rugose colony corrugation (Fig. 2), 


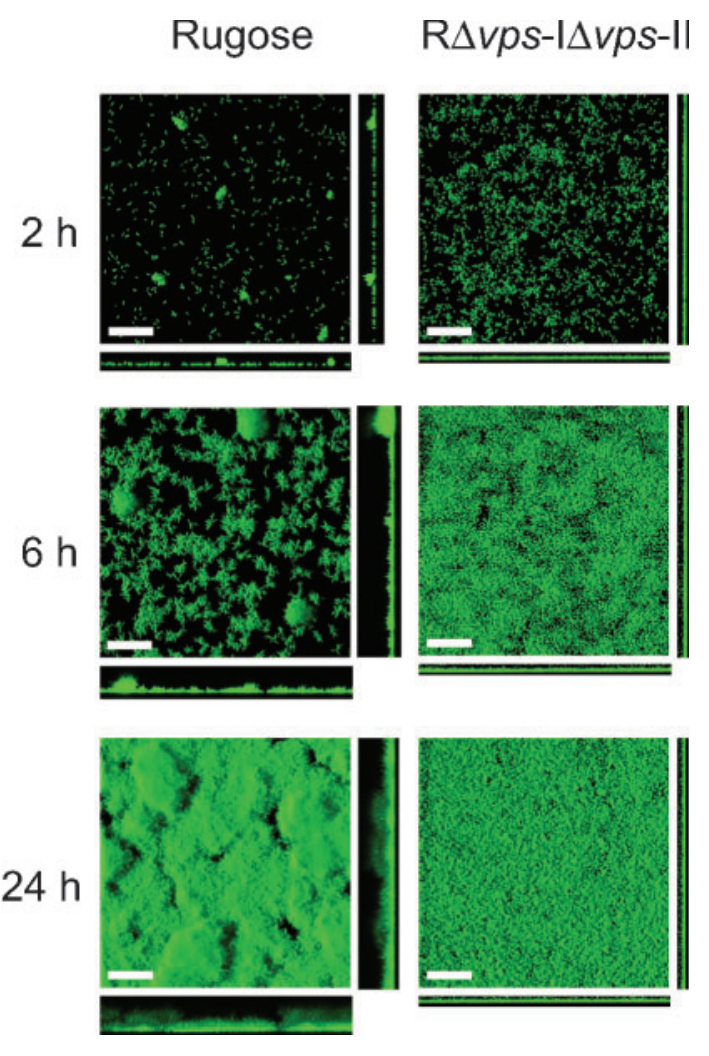

Fig. 5. Biofilm structure analysis of a $v p s$-clusters deletion mutant. CSLM images of horizontal $(x y)$ and vertical $(x z)$ projections (large and side panels, respectively) of biofilm structures formed by rugose wild-type and a mutant strain unable to produce VPS (R $\Delta v p s-I \Delta v p s-I I)$ are shown; scale bars represent $40 \mu \mathrm{m}$. Assays were repeated with at least two biological replicates.

formed a pellicle with structure similar to the rugose variant (Fig. 3) and did not exhibit significant defects in biofilm formation on solid surfaces or VPS production (Fig. 4). The structural modification of alginate by $\mathrm{O}$-acetylation alters its physical properties, including viscosity (Nivens et al., 2001). O-Acetyl groups are required for the formation of mature biofilm structures in alginate-producing mucoid
$P$. aeruginosa strains, as well as for maintenance of chronic $P$. aeruginosa infections (Pier et al., 2001). VPS is highly viscous, and thus non-acetylated VPS may have reduced viscosity, affecting biofilm structure and stability. While the altered rugosity-associated phenotypes exhibited by $\mathrm{R} \Delta v p s G$ are expected, it is surprising that $\mathrm{R} \Delta v p s C$ formed colonies and pellicles that resemble those of the rugose parent. We also generated a strain carrying in-frame deletions of both $v p s C$ and $v p s G$. This double mutant exhibited phenotypes similar to those of the single $v p s G$ mutant (Figs 2, 3 and 4). It is possible that $\mathrm{VpsC}$ is not a functional acetyltransferase, or that $\mathrm{VpsG}$ and $\mathrm{VpsC}$ may be required for the modification of different portions of the VPS, or even that these different acetyltransferase may be required at different stages of biofilm formation. We are currently testing these hypotheses.

Class $\mathrm{V}$ consists of the phosphotyrosine-protein phosphatase encoded by $v p s U$, and deletion of $v p s U$ resulted in a strain with altered colony morphology (Fig. 2), pellicle structure (Fig. 3), biofilm formation and VPS production (Fig. 4). Phosphotyrosine-protein phosphatases catalyse the dephosphorylation of tyrosine-phosphorylated proteins (Kennelly \& Potts, 1999). A number of phosphotyrosineprotein phosphatases in both Gram-positive and Gramnegative bacteria have been identified (Morona et al., 2000, 2002; Soulat et al., 2002; Vincent et al., 1999), and have been shown to be involved in regulation of exopolysaccharide production (Morona et al., 2000; Vincent et al., 2000). The phosphotyrosine-protein phosphatases found in Gram-negative bacteria usually contain two conserved active-site sequence motifs (C- $\mathrm{X}_{4}-\mathrm{C}-\mathrm{R}$ and D-P-Y) (Kennelly \& Potts, 1999; Su et al., 1994; Vincent et al., 1999), while those found in Gram-positive bacteria usually contain four conserved motifs (Aravind \& Koonin, 1998; Morona et al., 2002), except for PtpA and PtpB from $S$. aureus, which resemble phosphotyrosine-protein phosphatases found in Gram-negative bacteria (Soulat et al., 2002). Alignment of VpsU (V. cholerae), Wzb (E. coli), PtpA (P. aeruginosa $\mathrm{PAO} 1)$ and $\mathrm{PtpAB}(S$. aureus) indeed showed that $\mathrm{VpsU}$ contains the two active-site motifs conserved in other similar phosphotyrosine-protein phosphatases (data not shown). The altered rugosity-associated phenotypes

Table 3. COMSTAT analysis of biofilms formed by rugose wild-type and RAvps-Ivps-II

Values are means (standard deviations) of data from at least six $z$-series image stacks.

\begin{tabular}{|lcccc|}
\hline \multirow{2}{*}{ Strain } & Time $(\mathbf{h})$ & \multicolumn{2}{c|}{ Thickness $(\boldsymbol{\mu m})$} & \multirow{2}{*}{ Biomass $\left(\mathbf{\mu m}^{\mathbf{3}} \boldsymbol{\mu m}^{\mathbf{- 2}}\right)$} \\
\cline { 3 - 4 } & & Mean & Maximum & \\
\hline Rugose & 2 & $2.4(1.56)$ & $24.1(9.07)$ & $1.7(1.00)$ \\
& 6 & $6.8(1.89)$ & $36.4(9.24)$ & $5.7(1.40)$ \\
R $\Delta v p s$-I $\Delta$ sps-II & 24 & $30.8(3.65)$ & $60.9(7.98)$ & $25.5(2.97)$ \\
& 2 & $3.2(1.80)$ & $10.0(1.59)$ & $2.4(1.30)$ \\
& 6 & $8.6(1.48)$ & $13.0(1.91)$ & $7.5(1.42)$ \\
& 24 & $8.9(2.86)$ & $14.3(3.58)$ & $7.7(2.37)$ \\
\hline
\end{tabular}


exhibited by $\mathrm{R} \Delta v p s U$ indicate a role of $\mathrm{Vps} \mathrm{U}$ in VPS production, although the target for $\mathrm{Vps} \mathrm{U}$ remains to be determined. In E. coli, Wzb (phosphotyrosine-protein phosphatase) and Wzc (protein-tyrosine kinase) function together in the production of the capsular polysaccharide colanic acid (Vincent et al., 2000). Although the UniProt database suggested that $\mathrm{VpsO}$ is similar to the chain length determinant protein Wzz based on the presence of a PF02706 domain, BLASTP search using Wzc peptide sequence identified $\mathrm{VpsO}$ as the top match (E-value $4.6 \times 10^{-22}$ ), suggesting that $\mathrm{VpsO}$ may be the target of $\mathrm{VpsU}$. We are currently investigating this hypothesis.

Class VI consists of hypothetical proteins encoded by $v p s F$, $v p s J, v p s M, v p s P$ and $v p s Q$. While $\mathrm{R} \Delta v p s P$ and $\mathrm{R} \Delta v p s \mathrm{Q}$ strains produce VPS and form colonies, pellicles and biofilms similar to those of the wild-type, other mutants lacking $v p s F, v p s J$ and $v p s M$ exhibited complete loss of colony corrugation, inability to form pellicle and drastic reduction in biofilm formation and VPS production (Figs 2, 3 and 4 ). Since $v p s F, v p s J$ and $v p s M$ are predicted to encode hypothetical proteins, identifying the roles of these hypothetical proteins in building the biofilm matrix is critical.

Collectively, phenotypic analysis of the $v p s$ mutants shows that, under our experimental conditions, most of the VPS proteins are required for wild-type rugose colony corrugation, pellicle and biofilm formation, and VPS production.

\section{Role of biofilm matrix components in in vivo fitness}

$V$. cholerae biofilm formation inside the host and its contribution to pathogenesis is not well understood. While some biofilm-related factors have been studied for their roles in V. cholerae intestinal colonization (Lauriano et al., 2004; Rashid et al., 2004; Watnick et al., 2001; Zhu \& Mekalanos, 2003), different research groups have obtained contradictory results regarding the importance of these factors. For example, mutants lacking VpsR, a positive transcriptional regulator of biofilm matrix production, have given variable results for mouse infection, including normal and decreased colonization (Rashid et al., 2004; Tischler \& Camilli, 2005). In another study, a rugose variant (resulting from flaA deletion) was found to be defective for infant mouse intestinal colonization in a competition infection, suggesting that a high level of VPS production is detrimental (Watnick et al., 2001). It is therefore evident that many factors, possibly including the presence of VPS and matrix proteins, affect in vivo fitness of $V$. cholerae.

To this end, we carried out experiments to investigate whether known biofilm determinants in $V$. cholerae contribute to pathogenesis. We initially performed competition experiments using the smooth (low-biofilmforming) and rugose (high-biofilm-forming) wild-type variants in the commonly used infant mouse model, but did not see a significant difference in the competitive index (data not shown). We reasoned that competition assays alone may be misleading, as VPS produced by the rugose variant could complement the co-inoculated strain in trans, thus masking differences in in vivo fitness. Therefore, we performed single-strain infections in the infant mouse model. We first compared the colonization capacities of smooth and rugose wild-type variants. As shown in Fig. 6, the rugose variant colonized the intestine better (approx. 3.6-fold) than the smooth variant. These data suggest that matrix components contribute to colonization and increase in vivo fitness, since the rugose variant produces more biofilm matrix than the smooth variant. To test this hypothesis, we compared the colonization capacity of the rugose wild-type variant to those of a mutant that is incapable of producing VPS (R $\Delta v p s$-I $\Delta v p s$-II) and mutants that are unable to produce matrix proteins (R $\Delta r b m A$ and $\mathrm{R} \Delta r b m C \Delta b a p 1) . \mathrm{RbmA}, \mathrm{RbmC}$ and Bap1 matrix proteins modulate rugosity-associated phenotypes (Fong \& Yildiz, 2007; Fong et al., 2006). RbmC and Bap1 share $46.7 \%$ peptide sequence similarity and appear to be partially redundant. Deletion of rbmA and bap1 in the rugose genetic background resulted in strains with altered colony morphology and biofilm formation when compared to the rugose wild-type (Fong \& Yildiz, 2007; Fong et al., 2006). Although deletion of $r b m C$ (a homologue of bap1) in the rugose genetic background did not alter the colony morphology and biofilm formation significantly, the

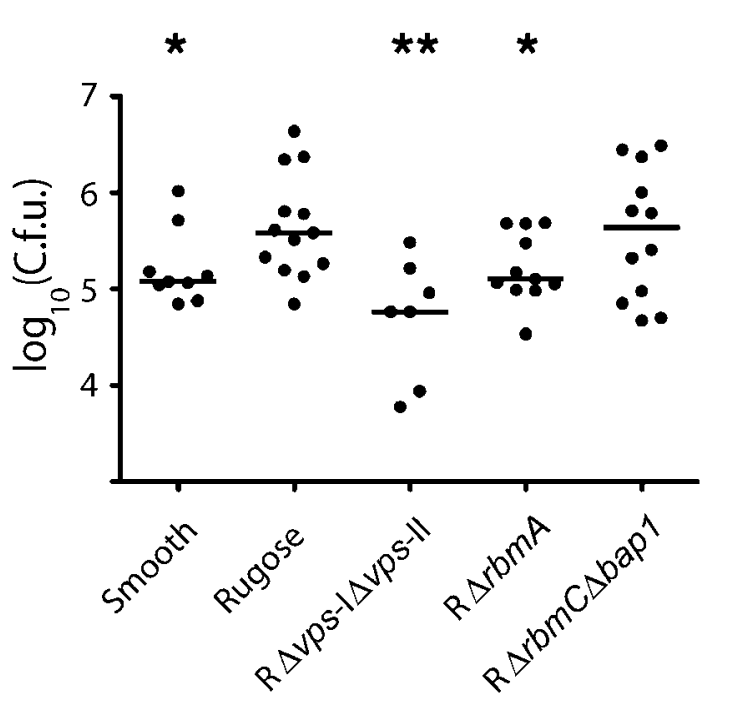

Fig. 6. Intestinal colonization phenotypes of $V$. cholerae wild-type and mutant strains in the infant mouse model. Wild-type smooth and rugose variants and rugose mutant strains lacking the genes required for VPS (R $\Delta v p s-I \Delta v p s-I I)$ and matrix protein production (R $\Delta r b m A$ and $\mathrm{R} \Delta r b m C \Delta b a p 1)$ were used in single-strain infections. The data shown are pooled from two experiments, and the horizontal bars indicate the median of each dataset. The asterisks indicate significantly different medians of the recovered c.f.u. compared to the rugose variant as determined by Mann-Whitney $U$ test (smooth $P=0.0354, \mathrm{R} \Delta v p s-\mathrm{I} \Delta v p s-\mathrm{II} P=0.0043$ and $\mathrm{R} \Delta r b m A P=0.0426)$. 
double deletion mutant $\mathrm{R} \Delta r b m C \Delta b a p 1$ exhibited a marked decrease in biofilm formation (Fong \& Yildiz, 2007).

We determined that $\mathrm{R} \Delta v p s$-I $\Delta v p s$-II exhibited a severe defect in intestinal colonization, with a 9.4-fold lower c.f.u. recovery compared to the rugose variant. This result indicates that VPS production increases in vivo fitness. The mutant lacking the biofilm matrix protein RbmA also exhibited a defect in intestinal colonization, with a 4.1-fold lower c.f.u. recovery. This outcome indicates that VPS and RbmA contribute significantly to in vivo fitness of $V$. cholerae in these models, and that they contribute to biofilm formation in both in vivo and aquatic environments. In contrast, there was no significant difference in the colonization ability of the R $\Delta r b m C \Delta b a p 1$ double mutant when compared to the rugose variant, indicating that either RbmC and Bap1 do not significantly influence intestinal colonization, or their phenotype is not evident under the experimental conditions utilized, thus suggesting that the major function of these biofilm matrix proteins is in the formation of biofilms in aquatic environments. Collectively, these results indicate that the biofilm matrix components are important in in vitro biofilm formation, and that VPS and RbmA also contribute to in vivo fitness of $V$. cholerae.

The results presented in this study have revealed how the various $v p s$ gene products contribute to wild-type biofilm formation and VPS biosynthesis, and have laid the groundwork for future biochemical characterization of the VPS biosynthetic pathway. In vitro experiments carried out with the $v p s$ mutants in this study, and $r b m$ mutants in previous studies, clearly demonstrate the importance of matrix components, both VPS and matrix proteins, in the building of a robust wild-type biofilm. In-frame deletion of 15 of the $18 v p s$ genes resulted in strains that exhibited drastic altered rugosity-associated phenotypes (Figs 2, 3 and 4). VPS and RbmA also contribute to in vivo fitness of $V$. cholerae, as shown in in vivo mouse colonization studies, where mutants not able to produce VPS or RbmA were defective for intestinal colonization (Fig. 6).

Humans ingest $V$. cholerae biofilms as part of the pathogen's normal transmission route. In this study, we have shown that VPS and biofilm matrix proteins are critical for in vitro biofilm formation and are also important for in vivo fitness. The nature of the VPS coating and matrix proteins in the biofilms may influence the progression of the disease, and/or development of an immune response against $V$. cholerae. A better understanding of biofilm matrix biosynthesis and function could allow us to develop inhibitors that specifically alter the matrix properties and affect either ex vivo (aquatic) survival or in vivo pathogenesis.

\section{ACKNOWLEDGEMENTS}

This study was supported by grants AI055987 to F. H. Y and AI43486 to K.E.K. The authors also thank N. Shikuma for his help in generating the following deletion strains: $\mathrm{R} \Delta v p s C, \mathrm{R} \Delta v p s F, \mathrm{R} \Delta v p s H$, $\mathrm{R} \Delta v p s I, \mathrm{R} \Delta v p s K, \mathrm{R} \Delta v p s L, \mathrm{R} \Delta v p s N$ and $\mathrm{R} \Delta v p s O$.

\section{REFERENCES}

Alam, M., Sultana, M., Nair, G. B., Sack, R. B., Sack, D. A., Siddique, A. K., Ali, A., Huq, A. \& Colwell, R. R. (2006). Toxigenic Vibrio cholerae in the aquatic environment of Mathbaria, Bangladesh. Appl Environ Microbiol 72, 2849-2855.

Aravind, L. \& Koonin, E. V. (1998). Phosphoesterase domains associated with DNA polymerases of diverse origins. Nucleic Acids Res 26, 3746-3752.

Bao, Y., Lies, D. P., Fu, H. \& Roberts, G. P. (1991). An improved Tn7based system for the single-copy insertion of cloned genes into chromosomes of gram-negative bacteria. Gene 109, 167-168.

Beyhan, S. \& Yildiz, F. H. (2007). Smooth to rugose phase variation in Vibrio cholerae can be mediated by a single nucleotide change that targets c-di-GMP signalling pathway. Mol Microbiol 63, 995-1007.

Beyhan, S., Bilecen, K., Salama, S. R., Casper-Lindley, C. \& Yildiz, F. H. (2007). Regulation of rugosity and biofilm formation in Vibrio cholerae: comparison of VpsT and VpsR regulons and epistasis analysis of $v p s T$, $v p s R$, and hapR. J Bacteriol 189, 388-402.

Broza, M., Gancz, H., Halpern, M. \& Kashi, Y. (2005). Adult nonbiting midges: possible windborne carriers of Vibrio cholerae non-O1 non-O139. Environ Microbiol 7, 576-585.

Campbell, J. A., Davies, G. J., Bulone, V. \& Henrissat, B. (1997). A classification of nucleotide-diphospho-sugar glycosyltransferases based on amino acid sequence similarities. Biochem J 326, 929-939.

Cantarel, B. L., Coutinho, P. M., Rancurel, C., Bernard, T., Lombard, V. \& Henrissat, B. (2009). The Carbohydrate-Active EnZymes database (CAZy): an expert resource for glycogenomics. Nucleic Acids Res 37, D233-D238.

Colwell, R. R., Huq, A., Islam, M. S., Aziz, K. M., Yunus, M., Khan, N. H., Mahmud, A., Sack, R. B., Nair, G. B. \& other authors (2003). Reduction of cholera in Bangladeshi villages by simple filtration. Proc Natl Acad Sci U S A 100, 1051-1055.

de Lorenzo, V. \& Timmis, K. N. (1994). Analysis and construction of stable phenotypes in gram-negative bacteria with Tn5- and Tn10derived minitransposons. Methods Enzymol 235, 386-405.

Enos-Berlage, J. L. \& McCarter, L. L. (2000). Relation of capsular polysaccharide production and colonial cell organization to colony morphology in Vibrio parahaemolyticus. J Bacteriol 182, 55135520.

Faruque, S. M., Albert, M. J. \& Mekalanos, J. J. (1998). Epidemiology, genetics, and ecology of toxigenic Vibrio cholerae. Microbiol Mol Biol Rev 62, 1301-1314.

Faruque, S. M., Biswas, K., Udden, S. M., Ahmad, Q. S., Sack, D. A., Nair, G. B. \& Mekalanos, J. J. (2006). Transmissibility of cholera: in vivo-formed biofilms and their relationship to infectivity and persistence in the environment. Proc Natl Acad Sci U S A 103, 6350-6355.

Fong, J. C. \& Yildiz, F. H. (2007). The rbmBCDEF gene cluster modulates development of rugose colony morphology and biofilm formation in Vibrio cholerae. J Bacteriol 189, 2319-2330.

Fong, J. C. \& Yildiz, F. H. (2008). Interplay between cyclic AMP-cyclic AMP receptor protein and cyclic di-GMP signaling in Vibrio cholerae biofilm formation. J Bacteriol 190, 6646-6659.

Fong, J. C., Karplus, K., Schoolnik, G. K. \& Yildiz, F. H. (2006). Identification and characterization of $\mathrm{RbmA}$, a novel protein required for the development of rugose colony morphology and biofilm structure in Vibrio cholerae. J Bacteriol 188, 1049-1059. 
Franco, A. V., Liu, D. \& Reeves, P. R. (1998). The Wzz (Cld) protein in Escherichia coli: amino acid sequence variation determines $\mathrm{O}$-antigen chain length specificity. J Bacteriol 180, 2670-2675.

Fullner, K. J. \& Mekalanos, J. J. (1999). Genetic characterization of a new type IV-A pilus gene cluster found in both classical and El Tor biotypes of Vibrio cholerae. Infect Immun 67, 1393-1404.

Halpern, M., Broza, Y. B., Mittler, S., Arakawa, E. \& Broza, M. (2004). Chironomid egg masses as a natural reservoir of Vibrio cholerae nonO1 and non-O139 in freshwater habitats. Microb Ecol 47, 341-349.

Hang, L., John, M., Asaduzzaman, M., Bridges, E. A., Vanderspurt, C., Kirn, T. J., Taylor, R. K., Hillman, J. D., Progulske-Fox, A. \& other authors (2003). Use of in vivo-induced antigen technology (IVIAT) to identify genes uniquely expressed during human infection with Vibrio cholerae. Proc Natl Acad Sci U S A 100, 8508-8513.

Herrero, M., de Lorenzo, V. \& Timmis, K. N. (1990). Transposon vectors containing non-antibiotic resistance selection markers for cloning and stable chromosomal insertion of foreign genes in gramnegative bacteria. J Bacteriol 172, 6557-6567.

Heydorn, A., Nielsen, A. T., Hentzer, M., Sternberg, C., Givskov, M., Ersboll, B. K. \& Molin, S. (2000). Quantification of biofilm structures by the novel computer program COMSTAT. Microbiology 146, 23952407.

Hung, D. T., Zhu, J., Sturtevant, D. \& Mekalanos, J. J. (2006). Bile acids stimulate biofilm formation in Vibrio cholerae. Mol Microbiol 59, 193-201.

Huo, A., Xu, B., Chowdhury, M. A., Islam, M. S., Montilla, R. \& Colwell, R. R. (1996). A simple filtration method to remove planktonassociated Vibrio cholerae in raw water supplies in developing countries. Appl Environ Microbiol 62, 2508-2512.

Huq, A., Small, E. B., West, P. A., Huq, M. I., Rahman, R. \& Colwell, R. R. (1983). Ecological relationships between Vibrio cholerae and planktonic crustacean copepods. Appl Environ Microbiol 45, 275283.

Huq, A., Huq, S. A., Grimes, D. J., O’Brien, M., Chu, K. H., Capuzzo, J. M. \& Colwell, R. R. (1986). Colonization of the gut of the blue crab (Callinectes sapidus) by Vibrio cholerae. Appl Environ Microbiol 52, 586-588.

Huq, A., Colwell, R. R., Chowdhury, M. A., Xu, B., Moniruzzaman, S. M., Islam, M. S., Yunus, M. \& Albert, M. J. (1995). Coexistence of Vibrio cholerae $\mathrm{O} 1$ and $\mathrm{O} 139$ Bengal in plankton in Bangladesh. Lancet 345, 1249.

Kaper, J. B., Morris, J. G., Jr \& Levine, M. M. (1995). Cholera. Clin Microbiol Rev 8, 48-86.

Kawamura, T., Ishimoto, N. \& Ito, E. (1979). Enzymatic synthesis of uridine diphosphate $N$-acetyl-D-mannosaminuronic acid. J Biol Chem 254, 8457-8465.

Kawamura, T., Ichihara, N., Sugiyama, S., Yokota, H., Ishimoto, N. \& Ito, E. (1985). Biosynthesis of UDP- $N$-acetyl-D-glucosaminuronic acid and UDP- $N$-acetyl-D-mannosaminuronic acid in Micrococcus luteus. J Biochem 98, 105-116.

Kennelly, P. J. \& Potts, M. (1999). Life among the primitives: protein O-phosphatases in prokaryotes. Front Biosci 4, D372-D385.

Kierek, K. \& Watnick, P. I. (2003). Environmental determinants of Vibrio cholerae biofilm development. Appl Environ Microbiol 69, 5079-5088.

Lauriano, C. M., Ghosh, C., Correa, N. E. \& Klose, K. E. (2004). The sodium-driven flagellar motor controls exopolysaccharide expression in Vibrio cholerae. J Bacteriol 186, 4864-4874.

Lee, S. H., Butler, S. M. \& Camilli, A. (2001). Selection for in vivo regulators of bacterial virulence. Proc Natl Acad Sci U S A 98, 68896894.
Lin, W., Kovacikova, G. \& Skorupski, K. (2007). The quorum sensing regulator HapR downregulates the expression of the virulence gene transcription factor AphA in Vibrio cholerae by antagonizing Lrp- and VpsR-mediated activation. Mol Microbiol 64, 953-967.

Lombardo, M. J., Michalski, J., Martinez-Wilson, H., Morin, C., Hilton, T., Osorio, C. G., Nataro, J. P., Tacket, C. O., Camilli, A. \& other authors (2007). An in vivo expression technology screen for Vibrio cholerae genes expressed in human volunteers. Proc Natl Acad Sci U S A 104, 1822918234.

Marolda, C. L., Vicarioli, J. \& Valvano, M. A. (2004). Wzx proteins involved in biosynthesis of $\mathrm{O}$ antigen function in association with the first sugar of the O-specific lipopolysaccharide subunit. Microbiology 150, 4095-4105.

Marolda, C. L., Tatar, L. D., Alaimo, C., Aebi, M. \& Valvano, M. A. (2006). Interplay of the $\mathrm{Wzx}$ translocase and the corresponding polymerase and chain length regulator proteins in the translocation and periplasmic assembly of lipopolysaccharide $\mathrm{O}$ antigen. $J$ Bacteriol 188, 5124-5135.

Morona, J. K., Paton, J. C., Miller, D. C. \& Morona, R. (2000). Tyrosine phosphorylation of CpsD negatively regulates capsular polysaccharide biosynthesis in Streptococcus pneumoniae. Mol Microbiol 35, 14311442.

Morona, J. K., Morona, R., Miller, D. C. \& Paton, J. C. (2002). Streptococcus pneumoniae capsule biosynthesis protein CpsB is a novel manganese-dependent phosphotyrosine-protein phosphatase. J Bacteriol 184, 577-583.

Nivens, D. E., Ohman, D. E., Williams, J. \& Franklin, M. J. (2001). Role of alginate and its $O$ acetylation in formation of Pseudomonas aeruginosa microcolonies and biofilms. J Bacteriol 183, 1047-1057.

Pier, G. B., Coleman, F., Grout, M., Franklin, M. \& Ohman, D. E. (2001). Role of alginate $O$ acetylation in resistance of mucoid Pseudomonas aeruginosa to opsonic phagocytosis. Infect Immun 69, 1895-1901.

Rashid, M. H., Rajanna, C., Zhang, D., Pasquale, V., Magder, L. S., Ali, A., Dumontet, S. \& Karaolis, D. K. (2004). Role of exopolysaccharide, the rugose phenotype and VpsR in the pathogenesis of epidemic Vibrio cholerae. FEMS Microbiol Lett 230, 105-113.

Sau, S., Bhasin, N., Wann, E. R., Lee, J. C., Foster, T. J. \& Lee, C. Y. (1997). The Staphylococcus aureus allelic genetic loci for serotype 5 and 8 capsule expression contain the type-specific genes flanked by common genes. Microbiology 143, 2395-2405.

Soulat, D., Vaganay, E., Duclos, B., Genestier, A. L., Etienne, J. \& Cozzone, A. J. (2002). Staphylococcus aureus contains two lowmolecular-mass phosphotyrosine protein phosphatases. J Bacteriol 184, 5194-5199.

Su, X. D., Taddei, N., Stefani, M., Ramponi, G. \& Nordlund, P. (1994). The crystal structure of a low-molecular-weight phosphotyrosine protein phosphatase. Nature 370, 575-578.

Tischler, A. D. \& Camilli, A. (2005). Cyclic diguanylate regulates Vibrio cholerae virulence gene expression. Infect Immun 73, 5873-5882.

Vasseur, P., Vallet-Gely, I., Soscia, C., Genin, S. \& Filloux, A. (2005). The pel genes of the Pseudomonas aeruginosa PAK strain are involved at early and late stages of biofilm formation. Microbiology 151, 985997.

Vincent, C., Doublet, P., Grangeasse, C., Vaganay, E., Cozzone, A. J. \& Duclos, B. (1999). Cells of Escherichia coli contain a proteintyrosine kinase, Wzc, and a phosphotyrosine-protein phosphatase, Wzb. J Bacteriol 181, 3472-3477.

Vincent, C., Duclos, B., Grangeasse, C., Vaganay, E., Riberty, M., Cozzone, A. J. \& Doublet, P. (2000). Relationship between exopolysaccharide production and protein-tyrosine phosphorylation in gram-negative bacteria. J Mol Biol 304, 311-321. 
Watnick, P. I., Lauriano, C. M., Klose, K. E., Croal, L. \& Kolter, R. (2001). The absence of a flagellum leads to altered colony morphology, biofilm development and virulence in Vibrio cholerae O139. Mol Microbiol 39, 223-235.

Whitfield, C. (1995). Biosynthesis of lipopolysaccharide O antigens. Trends Microbiol 3, 178-185.

Whitfield, C. (2006). Biosynthesis and assembly of capsular polysaccharides in Escherichia coli. Аnпu Rev Biochem 75, 39-68.

Yildiz, F. H. \& Schoolnik, G. K. (1999). Vibrio cholerae O1 El Tor: identification of a gene cluster required for the rugose colony type, exopolysaccharide production, chlorine resistance, and biofilm formation. Proc Natl Acad Sci U S A 96, 4028-4033.

Yildiz, F. H., Dolganov, N. A. \& Schoolnik, G. K. (2001). VpsR, a member of the response regulators of the two-component regulatory systems, is required for expression of $v p s$ biosynthesis genes and $\mathrm{EPS}^{\mathrm{ETr}}$-associated phenotypes in Vibrio cholerae O1 El Tor. J Bacteriol 183, 1716-1726.

Zhu, J. \& Mekalanos, J. J. (2003). Quorum sensing-dependent biofilms enhance colonization in Vibrio cholerae. Dev Cell 5, 647-656.

Edited by: V. Sperandio 